\title{
Betta splendens: Familiarity with visual cues fails to produce a prior-residence effect
}

\author{
PAUL M. BRONSTEIN \\ University of Michigan-Flint, Flint, Michigan
}

\begin{abstract}
Dominance/subordinancy relations in pairs of male Siamese fighting fish were assessed as a function of (1) familiarity with visual cues (colors) that sometimes were present during combat, and (2) the association of those familiar colors with agonistic experiences. Neither of these variables had any detectible influence on animals' becoming dominant. The probability of a fish's becoming dominant was not elevated by the visibility of familiar colors during combat. The pairing of familiar colors with precombat aggression also was without effect. However, the outcome of aggressive contests was significantly influenced by nonsocial stimulation administered to fish in the days prior to combat; the periodic placement of a water-filled jar into aquaria resulted, surprisingly, in an enormous elevation in the rate at which ties, or unresolved fights, occurred.
\end{abstract}

Domesticated Siamese fighting fish (Betta splendens) are Asian teleosts that exhibit an array of territorial-like social behaviors (see Bronstein, 1985c). Furthermore, males' territorial-like behaviors are, in part, mediated by learning. First, while living apart from other fish, male bettas become familiar with the visual and/or tactile characteristics of their environments, and this exposure learning produces the prior-residence effect (i.e., more tenacious and more successful fighting by fish in familiar surroundings; Bronstein, 1984, 1985b). Second, males learn the location from which social challenges to their privacy emanate, spend a disproportionately large amount of time near sites that have been associated with their mirror images, and exhibit agonistic, keep-out displays in those locales (Bronstein, 1986).

The current study was an attempt to extend the information about the learning potentials of bettas. Since exposure to arrays of visual and tactile cues increases the probability that males will become dominant in the presence of those cues, I inquired whether the probability of a fish's becoming dominant would be elevated when fighting occurred only in the presence, specifically, of familiar colors. Familiarity with colors mediates the priorresidence effect in other teleost species (Figler \& Einhorn, 1983); however, influence of such visual cues has not been shown for bettas. In addition, studies by Hollis (1984) and Hollis, Martin, Cadieux, and Colbert (1984) suggest that teleosts might be trained to become dominant over opponents by pairing neutral visual cues with aggression-

This paper was supported by grants from the Faculty Development Committee of the University of Michigan-Flint, Rackham Grants and a Rackham Fellowship from the University of Michigan-Ann Arbor, and by the National Institute of Mental Health (Grant MH 338792-01). I am grateful to Larry Atherton, Jr., and William Mykolajenko for their excellent technical aid and to Sharon Mittan for her secretarial assistance.

Requests for reprints should be sent to Paul M. Bronstein, Department of Psychology, University of Michigan-Flint, Flint, MI 48502 2186. eliciting stimuli. A recent set of experiments (Bronstein, 1986) suggests that such Pavlovian procedures also may be effective in producing a dominant social status among male bettas; this hypothesis was also examined.

\section{METHOD}

Adult and experimentally naive male bettas were purchased from a local supplier and maintained in visual isolation in individual glass jars $(945 \mathrm{ml})$ for at least 2 weeks prior to the start of the experiment. The laboratory was kept at $27^{\circ} \pm 2^{\circ} \mathrm{C}$, with lights on from 0800 to $2200 \mathrm{~h}$. Water for all stages of the study was tap water aged at least $24 \mathrm{~h}$ and in which no other animal had swum. Five days per week (Monday through Friday) fish were fed once daily with a dry flake food, and once per day with recently thawed adult brine shrimp (Artemia spp.).

Each fish was netted and placed into an individual all-glass tank for a 12-day residency phase, during which fish were in visual isolation. Each tank $(51 \times 26 \mathrm{~cm})$ had undyed gravel flooring, had transparent plastic and glass covers, and was filled with water to a depth of $9 \mathrm{~cm}$. In the manner of earlier dominance studies (Bronstein, 1984), gravel was piled to or slightly above the water line in each corner of the tanks, and four dividers of colored plastic $(12.7 \mathrm{~cm}$ long, $3 \mathrm{~mm}$ thick, and protruding 1-2 cm above the water line) were planted on edge in each tank; these dividers radiated from near the centers of the aquaria toward the four corners of the tanks. This geometric arrangement permits fish to swim throughout the tank and around each barrier. Also, when animals engage in combat in these aquaria, the plastic barriers permit effective escape so that one fish is rarely injured severely by another (Bronstein, 1984). All four dividers in each tank were colored either red or green by covering 1-mm-thick sheets of white perforated styrene on both sides with either red or green plastic tape (3M Scotch Brand, Cat. Nos. 191 $\& 193$ ). All surfaces of the plastic dividers were then coated with a thin layer of clear silicon cement in order to eliminate any water-borne chemical cues associated with the different tape colors.

Ninety-eight pairs of male residents were established. Each dyad was composed of subjects that (1) were judged by visual inspection to be the same size (cf. Bronstein, 1984, 1985a), (2) were of different colors (red, purple, or blue-green), and (3) had shown some agonistic gill-cover display when presented with a mirror for $3 \mathrm{~min}$ on the outside of their home containers during the week prior to the study. Also, of each pair of subjects, 1 male spent its residency period in contact with red dividers, and the partner with green dividers.

Dominance testing began on the morning of Day 13 and was accomplished by netting both members of a pair and simultaneously placing them into a fresh test tank. These test aquaria contained either red or 
green dividers and were identical in configuration to the residency tanks. Following 24-28 $\mathrm{h}$ of cohabitation and fighting, the social positions of the fish were assessed by either 2 or 3 independent observers. A fish was judged dominant (1) if its opponent was dead, or (2) if it approached its opponent and issued gill-cover displays and if that opponent moved away from the charging animal without ever exhibiting displays. As in previous studies (Bronstein, 1984), dominance judgments among observers were perfectly reliable.

Three independent groups were established, each having different experiences during the 12-day prefight residency period. First, a sociallearning group ( $n=38$ pairs) was stimulated to aggression by a male betta for fifteen 40-min periods (on the afternoon of Day 1 and on both the mornings and afternoons of Days 4, 5, 6, 7, 8, 11, and 12). Social stimulation, which paired a distinctive and discriminable conditioned stimulus (the colored panels) with an aggression-eliciting unconditioned stimulus, involved placing a clear glass jar containing an aggressive male betta into the center of each residency tank (i.e., at the confluence of the four dividers). The bottles, with a square cross section $(7.62 \mathrm{~cm}$ on a side), had a water level equal to that of the residency tanks. Also, there were two aggression-eliciting stimulus fish per subject, with each stimulus male used once per day. Observations of subjects during their intermittent social stimulation revealed that all these social-learning animals attacked the stimulus animals in the species-typical manner (see Bronstein, 1985a). Second, a control group ( $n=30$ pairs) had bottles filled only with water placed into their tanks on a schedule identical to the stimulation regimen of the social-learning group. Fish, as expected, merely swam around and away from this clear glass bottle without exhibiting any distinctive pattern of behavior. Third, a group of isolates ( $n=30$ pairs) were, except for feeding, left undisturbed during the residency phase of the study. The test aquaria for approximately half the pairs of each group contained red dividers; the other tanks contained green inserts.

\section{RESULTS AND DISCUSSION}

The main findings of the current study, summarized in Table 1, were that the color of animals' prefight residency environments failed to influence the outcome of aggressive contests in the ways originally hypothesized. With ties (male-male contests resulting in ambiguous outcomes) excluded from the calculation, only $52 \%$ of fish fighting in tanks having the same color plastic as in their prefight aquaria became dominant. Similarly, a color match between residency and test environments was correlated with a fish attaining dominance for only $52 \%$ or $53 \%$ of the fish in each group. None of these rates of dominance attainment is statistically different from chance expectations; and none of the intergroup differences approached significance $(p s>.05)$. Thus, neither familiarity with these colors nor, in the case of the social-learning group, the pairing of the colors with attack behaviors and conspecific

Table 1

The Frequencies of Combat Outcomes

\begin{tabular}{lcccr}
\hline \multicolumn{1}{c}{ Groups } & $\boldsymbol{n}$ & $\begin{array}{c}\text { Color-Matched } \\
\text { Male* Wins }\end{array}$ & $\begin{array}{c}\text { Color-Matched } \\
\text { Male* Losses }\end{array}$ & Ties \\
\hline Social-Learning & 38 & 20 & 18 & 0 \\
Isolates & 30 & 14 & 13 & 3 \\
Controls & 30 & 10 & 9 & 11 \\
\hline
\end{tabular}

*Each contest was staged between 1 male fighting in a tank that contained plastic pieces having the same color as experienced during its precombat residency and 1 male fighting among plastic strips of novel coloration. The former fish are referred to as "color-matched." stimulation conferred any effective control of aggression upon those visual cues. The amount of experience associating these highly discriminable colors with conspecific aggression in the current study far exceeded that required to make those colored stimuli conditioned elicitors of both approach and aggressive display in bettas (Bronstein, 1986). Nevertheless, in no group was the attainment of dominance reliably increased for males fighting in familiar environments. There was one highly significant difference among the groups and behavioral categories shown in Table $1\left[3 \times 3 \chi^{2}(4)=18.54\right.$, $p<.001]$. In the empty-bottle control group, $37 \%$ of the contests did not result in a stable dominance/subordinancy relationship, whereas none of the fights in the sociallearning group and only $10 \%$ of the contests between isolates resulted in ties [ $\left.3 \times 1 \chi^{2}(2)=17.67, p<.001\right]$. After more than a day of cohabitation, $37 \%$ of control pairs either still persisted in mutual attacks or swam about their tanks without any attack or display occurring.

Further analyses (Fisher exact probability tests; Siegel, 1956) showed a reliable difference in the rate of ties between controls and social-learning dyads $(p=.00004)$, with the other two paired comparisons approaching significance $(p s<.09)$. The empty-bottle controls also were unlike the hundreds of male-male dyads tested previously under similar circumstances, but without physical disruption during the prefight residency period (Bronstein, 1984). Stable dominance/subordinancy relations in pairs of male bettas are typically achieved in all but about $10 \%$ of contests within a day after the start of fighting. Apparently, when male bettas are presented with physical disruption but no social stimulation prior to combat, some aspects of their subsequent aggression are disrupted, with the formation of dominance/subordinancy relations either delayed or prevented as a consequence. This highly robust but totally unexpected result cannot be deduced post hoc from any principles of learning or betta social behavior of which I am aware. However, these data show that male bettas assess the physical disruption, perhaps the water turbulence, of their environment in judging an area suitable for defense. The fish are relatively slow in resolving conflicts following a period of nonsocial, physical disruption.

\section{REFERENCES}

Bronstein, P. M. (1984). Agonistic and reproductive interactions in Betta splendens. Journal of Comparative Psychology, 98, 421-431. Bronstein, P. M. (1985a). Predictors of dominance in male Betta splendens. Journal of Comparative Psychology, 99, 47-55.

Bronstein, P. M. (1985b). Prior-residence effect in Betta splendens. Journal of Comparative Psychology, 99, 56-59.

Bronstein, P. M. (1985c). Toxiphobia, "social reinforcement," comparative psychology, and Patrick J. Capretta. In N. S. Braveman \& P. M. Bronstein (Eds.), Annals of the New York Academy of Sciences (pp. 158-170). New York: New York Academy of Sciences.

Bronstein, P. M. (1986). Socially mediated learning in male Betta splendens. Journal of Comparative Psychology, 100, 279-284. 
Figler, M. H., \& EINHORN, D. M. (1983). The territorial prior residence effect in convict cichlids (Cichlasoma nigrofasciatum Gunther): Temporal aspects of establishment and retention, and proximate mechanisms. Behaviour, 85, 157-183.

Hollis, K. L. (1984). The biological function of Pavlovian conditioning: The best defense is a good offense. Journal of Experimental Psychology: Animal Behavior Processes, 10, 413-425.
Hollis, K. L., Martin, K. A., Cadieux, E. L., \& Colbert, M. M. (1984). The biological function of Pavlovian conditioning: Learned inhibition of aggressive behavior in territorial fish. Learning \& Motivation, 15, 459-478.

SIEGEL, S. (1956). Nonparametric Statistics. New York: McGraw-Hill.

(Manuscript received for publication February 2, 1987.) 